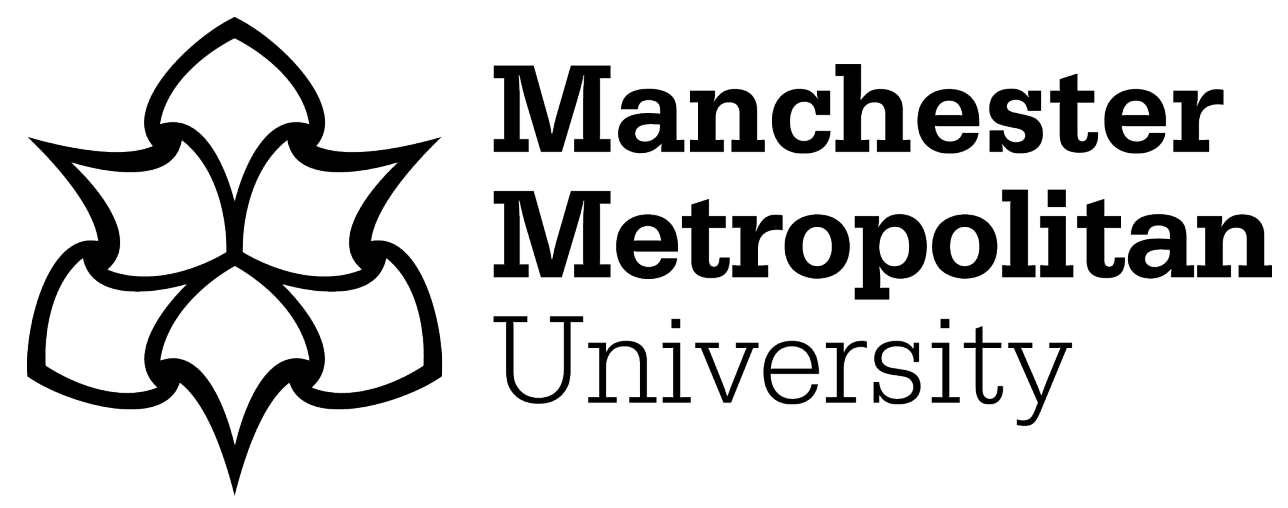

Brownbridge, K, Gill, S, Grogan, S, Kilgariff, S and Whalley, A (2018) Fashion misfit: women's dissatisfaction and its implications. Journal of Fashion Marketing and Management, 22 (3). pp. 438-452. ISSN 1361-2026

Downloaded from: https://e-space.mmu.ac.uk/620287/

Version: Accepted Version

Publisher: Emerald

DOI: https://doi.org/10.1108/JFMM-05-2017-0050

Please cite the published version 


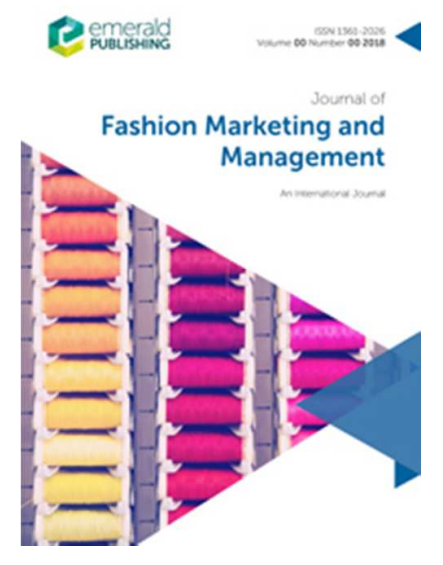

Fashion misfit: women's dissatisfaction and its implications

\begin{tabular}{|r|l|}
\hline Journal: & Journal of Fashion Marketing and Management \\
\hline Manuscript ID & JFMM-05-2017-0050.R1 \\
\hline Manuscript Type: & Original Article \\
\hline Keywords: & $\begin{array}{l}\text { Fashion, clothing fit, body image, Consumer satisfaction, textiles waste, } \\
\text { sizing systems }\end{array}$ \\
\hline \multicolumn{2}{|c}{} \\
\hline
\end{tabular}

SCHOLARONE

Manuscripts 


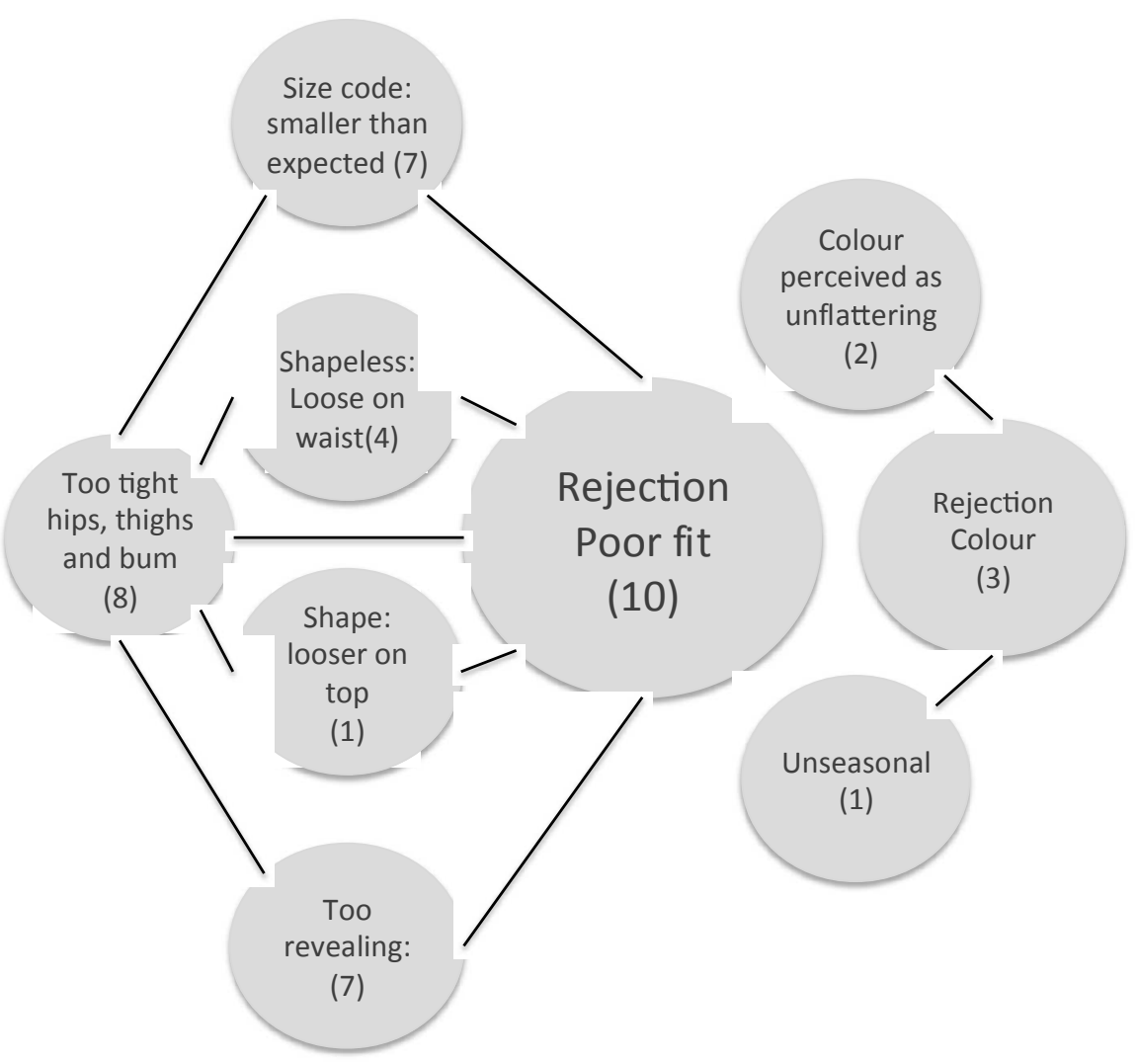

Figure 1 Themes and links between themes (numbers of women reporting each theme are in parentheses) 


\begin{tabular}{|c|c|c|c|c|c|}
\hline Retailer & Code & Description & Colour & Fabric & Cost \\
\hline \multirow[t]{2}{*}{$\overline{\mathrm{H} \& \mathrm{M}}$} & H\&M-PktTunic & $\begin{array}{l}\text { Plain garment with little bust, waist or } \\
\text { hip shaping. Garment cut as a simple } \\
\text { tunic style }\end{array}$ & $3 \times$ Pink & $\begin{array}{l}100 \% \\
\text { Polyester }\end{array}$ & $£ 24.99$ \\
\hline & H\&M-ShrtButtn & $\begin{array}{l}\text { Fitted style with shirt placket opening } \\
\text { to waist level, capped sleeves and collar } \\
\text { detail. }\end{array}$ & $3 \times$ Salmon & $\begin{array}{l}97 \% \text { Cotton } \\
3 \% \text { Elastane }\end{array}$ & $£ 24.99$ \\
\hline \multirow{3}{*}{ New Look } & \multirow{2}{*}{ NL-FCapeTea } & \multirow{2}{*}{$\begin{array}{l}\text { Fitted bodice, with flared skirt, capped } \\
\text { sleeves and collar detail. }\end{array}$} & 1 x Scarlet (10) & \multirow{2}{*}{$\begin{array}{l}100 \% \\
\text { Polyester }\end{array}$} & \multirow{2}{*}{$£ 27.99$} \\
\hline & & & $2 \times$ Blue $(12 / 14)$ & & \\
\hline & NL-Shrt & $\begin{array}{l}\text { Short sleeve, loose fit dress, with flared } \\
\text { lower skirt and unfitted bodice, belt } \\
\text { provided to cinch in waist and placket } \\
\text { opening to waist level }\end{array}$ & 3 x Blue Floral Print & $100 \%$ Viscose & $£ 27.99$ \\
\hline $\begin{array}{l}\text { Marks and } \\
\text { Spencer }\end{array}$ & M\&S-Twist & $\begin{array}{l}\text { Fitted dress style, with exposed CB zip } \\
\text { and twist detail above bust area on the } \\
\text { bodice }\end{array}$ & $6 \times$ Red & $\begin{array}{l}100 \% \\
\text { Polyester }\end{array}$ & $£ 39.50$ \\
\hline \multirow[t]{2}{*}{ Topshop } & TS-PItTunic & $\begin{array}{l}\text { Fitted tunic style, with exposed CB zip } \\
\text { and pleat detailing on the front of the } \\
\text { bodice. }\end{array}$ & $\begin{array}{l}1 \times \text { Purple }(10) \\
2 \times \text { Green }(12 / 14)\end{array}$ & $\begin{array}{l}\text { Main } 100 \% \\
\text { Polyester } \\
\text { Lining } 100 \% \\
\text { Acetate }\end{array}$ & $£ 46.00$ \\
\hline & TS-DrapeDtl & $\begin{array}{l}\text { Loose fitted, long sleeve, with slit } \\
\text { opening down CB. Skirt is full with } \\
\text { unfitted bodice, elastic and a belt at the } \\
\text { waist provides shaping. }\end{array}$ & $\begin{array}{l}2 \times \text { Cream and } \\
\text { Yellow }(10 / 12) \\
1 \times \text { Blue and Green } \\
(14)\end{array}$ & $\begin{array}{l}100 \% \\
\text { Polyester }\end{array}$ & $£ 55.00$ \\
\hline
\end{tabular}

Table 1 details of dresses 


\section{Fashion Misfit: women's dissatisfaction and its implications}




\section{Structured Abstract:}

\section{Purpose}

This study draws attention to under-developed and ill-informed sizing practices, fit dissatisfaction and the creation of textiles waste. The literature review identifies: issues that limit the effective development and application of sizing systems, the link between the complexities of consumer fit expectations, body image and self-esteem and maps the link between fit dissatisfaction and the creation of textiles waste.

Methodology

Data analysis draws from a wider study designed to investigate women's experiences of dress fit and body image. 20 women aged 18-45 years were audio-recorded while they tried on a number of mass-produced dresses, and were asked to select one dress, which they could keep.

Findings

All the dresses were selected except one style, which failed to satisfy any of the women's fit requirements. The findings identify why this dress was considered to be unsatisfactory and highlight the subsequent link between poor fit and body dissatisfaction.

Social implications

Findings support the theory that women identify with their clothes' size and when this link is disrupted it causes discomfort and body dissatisfaction which in turn contributed to rejection of the garment.

Originality/value

This study is the first to link unsatisfactory fashion sizing practice with the production of textiles waste. The process of capturing women's interactions with high street fashion dresses whilst trying them on, enabled a detailed analysis that contributes new evidence to the debate around sizing practice, poor fit and its impact on body image and self-esteem.

\section{Key words}

Sizing, fit, fashion, body image, consumer satisfaction, textiles waste 


\section{Introduction}

\section{The historical development of $U K$ women's sizing systems}

Sizing systems for mass-produced clothing should meet the size needs of a whole and varied population. However, systems both in the UK and globally have been the focus of much criticism both from academic authors (Beazley, 1998; Winks, 1997; Ashdown, 1998; Lee et al., 2007; Gill, 2015) and the popular press (Shabi, 2004; Fox, 2007; Smithers, 2011; Street Porter, 2016). This study provides further evidence to show that current methods of sizing are unsatisfactory and highlights the resulting implications on body image and the creation of textiles waste.

In the UK, clothing was constructed on an individual basis well into the $20^{\text {th }}$ century (Kunick, 1984; Aldrich, 2007). This individual approach enabled the tailor or dressmaker to adjust garments for each specific wearer. Manufacturing skills and the application of body measurement were developed within this context. The introduction of mass production, initially in America and later in Europe, eliminated the opportunity to fit on the individual. It is this change that initiated the need to solve a far more complex problem, involving statistical analysis of data sets and the development of new sizing systems. New skills and data sets were therefore in demand in the clothing industry.

To gather anthropometric data for mass-produced clothing, scientific sizing surveys were initiated. The first, in America during the 1940s, collected data from approximately 1500 female agricultural workers (O'Brian and Shelton, 1941). This became a model for future surveys including one in the UK, in 1951 (Kemsley 1957). The UK survey report recommended that at least three female body shapes should be considered in subsequent sizing systems (Kunick, 1984; Winks, 1997). However, British retailers' based their systems on only one body shape and up until fairly recently this practice remained unchanged (Bougourd, 2007; Gribbin, 2014). Sizing systems are influenced by two conflicting needs: to provide the most appropriately fitting garments for a population, and to reduce costs for the manufacturer (Ashdown, 1998; Ashdown, 2014). Basing systems on one body shape reduces the number of sizes, which can reduce costs for the manufacturer. Studies conducted in a variety of 
countries have demonstrated the limitations of this narrow approach when applied to large populations (Tamburrino, 1992a; Winks, 1997; Ashdown, 1998 Beazley, 1996; Lee et al., 2007; Gill, 2008). There is also evidence to show that sizing and grading practices predate these large scale surveys, raising questions regarding their grounding in population differences (Schofield and LaBat, 2005).

\section{Literature Review}

\section{Current problematic sizing practice}

A number of issues can be identified that result in problematic sizing practice including; subjective fit evaluation; the failure to recognise variances in body shape; changes in purchasing behaviour as a result of online consumption; and the preference for idealised body shapes within the fashion industry.

Many large scale sizing surveys, using 3D body scanning technologies, have been conducted globally ( $\mathrm{Yu}, 2004$; King, 2014). However in order to apply the survey findings effectively further research is required. Recent studies demonstrate that outmoded and inappropriate practice has prevailed in many clothing companies (Ashdown and O'Connell, 2006; Brownbridge, 2012; Gribbin 2014). To establish fit each individual prototype garment is fitted on a fit model, whose body conforms to a company's sample size (Pisut and Connell, 2007; Wren and Gill, 2010; Ashdown, 2014). This method replicates historical practice used when garments were constructed for individuals. Bye et al. (2008) evaluated industry grading practice and found that it did not provide good fit. They condemned commonly used sizing practice comprising of: fitting prototypes on a model who complies to a small sample size, grading this prototype to develop a range of sizes, failing to conduct any further fit tests. It was suggested that fit tests should be conducted throughout the size range. Although it may be logical to test the fit of prototypes, it is difficult to see how creating good fit on one person can achieve good fit for a population of people. In fact a previous study that compared 3D body data from 637 women and a retailer's fit model demonstrated that this method is not appropriate. Only nine of the women were found to conform to the bust waist and hip measurements of the fit model. Further visual analysis of the 3D images showed postural, height and proportional variance (Brownbridge et al. 2014). No matter how rigorous the fit testing process is, once the item of clothing is worn by anyone other than the fit model, the fit relationship 
changes and is likely to be compromised. In addition this method of achieving fit is said to rely on subjective personal judgement (Fan et al., 2004; Ashdown and O'Connell 2006) and create bottlenecks and expensive iterations within the product development cycle (Brownbridge 2012).

The failure to recognise more than one body shape within a population has been discussed in previous studies (Gill and Brownbridge, 2015; Gribbin, 2014). Although there may be production savings when producing a reduced number of sizes, there must also be a cost related to the alienation of consumers who are dissatisfied with fit and the inevitable returns of clothes to retailers. This is of particular concern because the online sector eliminates the ability to try garments on before purchase and is becoming increasingly popular. It is perhaps understandable therefore that $54 \%$ of young women, aged 16-24 have said that they have returned clothes bought online and nearly half of these blame poor fit for their dissatisfaction (Goody, 2016).

An issue that is more reflective of the aspirational nature of fashion is the use of idealised bodies during design and development processes. This has led to a focus on slim female bodies. Designs are conceptualised on exaggeratedly tall slim templates (Brownbridge, Gill and Sanderson 2014). Garments tend to be produced for a slim female body (in the UK a size 10 or 12) (Jenkin Jones 2005; Bougourd 2007), yet according to the findings from SizeUK (Taylor 2004) the average woman is larger than a size 10 or 12 . If designers and product developers are predominantly focusing on slim female bodies they are unlikely to be addressing the specific preferences of the increasing number of larger women. Studies show that women tend to have very specific preferences according to their body size and shape (Apeagyei, 2008; Grogan et al., 2013). This tendency to only use idealised body shapes must surely have a negative impact on the ability to satisfy the preferences of a varied population.

\section{Non-standard and inconsistent sizing provision}

Any attempts to introduce sizing standardization at a national level, let alone globally have failed (Winks 1997). It is left up to each individual retailer to develop their own system of sizing. This current lack of standardization has been claimed to create more choice for the consumer (Workman 1991) and this opinion is often cited in popular discussion of sizing (Hardy, 2011; Shabi, 2004). It is hard to see how such a haphazard approach presents a solution. In fact, it causes much confusion as sizes 
between retailers vary so much. Whilst there is evident variation in UK sizing (Gill, 2016) this does not equate to similar variation in proportional (shape) offerings in existing sizing (Gill, 2015).

Size coding used to communicate the size of the garment to the consumer presents further opportunities for inconsistency and non-standardisation. Both the methods of communicating size and the amount of increment between sizes vary (Winks, 1997). Kinley (2003) recognised the frustration that sizing inconsistency causes women and investigated the extent to which sizes vary on the high street. An evaluation was conducted on trousers,. 1011 pairs were measured at the waist, inseam and crotch. Measuring garments bought from retailers to establish variance is not an exact science, as it is difficult to distinguish between dimensional variance caused by styling choices from those caused by size chart variance. The study did however indicate a large degree of dimensional inconsistency across a range of providers within single sizing categories. Kinley (2003) recommended a de-emphasise of the number on the size label in order to focus on achieving comfort through appropriate fit.

A more recent study collected all the published size chart data from UK retailers and presented it in a visual format to guide consumers (Powell-Smith, 2012). This study highlights sizing inconsistency in the UK and the generous press attention received by this work indicates a high level of public interest. Vanity sizing, a strategy used by retailers to flatter women into thinking they are a smaller size than they expect to be (Shabi, 2003) has also been criticised for creating further inconsistency between retailers (Labat, 2007, Kennedy 2009). Size coding systems are not being used as a consistent means to communicate garment size, but as a marketing tool. Further complicated by the global nature of the industry, often resulting in the inclusion of multiple size codes from various global regions on one label (British Standards Institute, 2002).

\section{Garment fit and the female body}

If sizing systems consistently fail to meet the fit needs of a broad range of consumers, the subsequent implications are more than just economic losses for the retailer. The way a garment fits a person has been found to signal a range of subtle messages to the wearer about their body. Women can monitor changes of body size by the fit of their clothes. They identify with their clothes' size and blame their own 
bodies if clothes do not fit. This can impact on body image, self esteem and identity (Labat and DeLong 1990; Grogan et al. 2013; Grogan 2016;).

This present study presents a very focused analysis of apparel related data from a larger interdisciplinary study, which interviewed and observed women when they were trying dresses on. The initial output focussed on the women's comments in relation to dress fit and body image (Reference blinded for peer review). The thematic analysis found a consistent preference for the slim hourglass body shape. These aspirational preferences influenced the choices women made; they tended to seek garments that balanced the hip and bust dimensions, created a well-defined waist, and avoided styles that made them feel larger. Participants wanted the dresses to conceal body regions that they thought were unattractive or socially inappropriate and emphasise regions that they thought enhanced their attractiveness. The desire to conform to the slim hourglass body relates to the idealised fashion body used by the industry for shop mannequins, catwalk models and models used to sell clothing online.

De Klerk and Tselepis (2007) explored the relationship between fit evaluation, fit expectation and fit satisfaction for adolescent female consumers. They found that consumer fit preferences were influenced by a range of characteristics, such as comfort, the ability to flatter the body, suitability for the occasion and adherence to current fashion. Apeagyei (2008) found that $77 \%$ of survey respondents experienced problems with garment fit relating to specific problematic body locations. They sought clothes that enhanced their body shape and were aware if their own body shape did not conform to industry standards. Shim and Bickle (1993) focused on women aged 55 and over. Differences in fit satisfaction between tall, medium and petit women were compared. This study demonstrated that satisfaction levels were low and identified specific issues such as length of trousers, skirts and dresses as problematic. Indication that sizing systems were not catering for a diverse range of heights was evident. It was recommended that retailers should address this lack of diversity and introduce sizing systems that cater for various heights and different ages. 25 years later, most fashion retailers are still operating limited sizing systems and fit problems are still manifest.

Eckman et al. (1990) included fit analysis within a broader context whilst exploring the decision making processes, consumers experience when purchasing apparel. 80 women were interviewed in two stores in the same city. The women were 
only questioned after they had tried garments on, so observation on how the garments were selected were retrospective. Three decision making phases were identified; the selection of the garment (the interest phase), the trial phase (in the changing room) and the purchase decision (to buy or reject). Results suggested that women focus on different characteristics during the initial selection of the garment (colour/pattern, styling and fabric) than they do when they decide to purchase a garment (fit and appearance) or reject a garment (fit, appearance and styling).

All these studies show that fit assessment at an individual level is subtle and complex and women's fit expectations relate to interpretations of bodily aspirations. If these expectations are not acknowledged by fashion product developers the subsequent garments are more likely to remain unsold or returned post purchase.

\section{The clothing industry's contribution to waste}

Unsold garments and returns are both signifiers of non-sustainable fashion practice. A growing number of studies are acknowledging that current fashion systems do not comply with definitions of sustainability. Cataldi et al. (2013) blame fast fashion production for causing serious environmental damage including: the depletion of fossil fuel and fresh water reservoirs; contamination through pesticides use and synthetic fibre production and the release of toxic waste water pollutants. Given that the production of clothing can be so harmful it is appalling that such a high percentage is discarded so casually. According to Fletcher (2014) 1.1 million tonnes of textiles (approximately $18 \mathrm{~kg}$ per person) are discarded every year in the UK. Lapolla and Sanders (2015) reported on figures from the environmental protection agency of just over 41 kilos of clothing and textiles wasted per person every year in the US. Textiles waste in landfill sites produces methane emissions, pollutes the ground and can contaminate water systems. Levels of waste disposal appear to be growing as consumption levels rise (Fletcher 2014).

Waste is also generated by the production of fashion ranges that are rejected by the consumer and never leave the store, forcing redistribution (Grose, 2013). Businesses like TK Maxx buy up and sell unsuccessful lines. The vast scale of this global player is an indication of how significant the quantities of unsold fashion goods are. Even more worrying are the reports of clothing being sent straight from the shop to landfill. $H \& M$ and Walmart have both been accused of slashing or damaging unsold clothing, before leaving it out for municipal rubbish clearance providers 
(Dwyer, 2010). Reports also claim that faulty goods are incinerated even before they get into the store (Grose 2013).

The link between inconsistent and limited sizing systems and the creation of textiles waste has not been previously addressed. This study identifies the relationship between current sizing practice and waste creation, by analysing responses about one particular dress, which was rejected by $100 \%$ of women in the larger study focusing on dress fit and body image (reference blinded for peer review).

\section{Methodology}

The project involved a multi-disciplinary team of researchers from Manchester Metropolitan University and Health Psychology researchers from Staffordshire University. Qualitative data were collected whilst participants were trying garments on, and in subsequent interviews (see reference blinded for peer review for linked psychology research from the larger study). A variety of dress styles were purchased from four UK retailers (see table 1). Participants were told that they could take one of these dresses home with them. At the end of the data collection period, all the dresses had been selected except one particular style. The data analysis for this study seeks to determine the reasons why this dress remained on the rails, rejected by all 20 participants.

\section{Recruitment of Participants}

20 Participants were recruited by word of mouth and email, sent initially through a university network then snowballing to include a wider demographic. This study was designed as an in depth, qualitative study and therefore the number of participants were limited to 20 in order to enable a thorough analysis of the rich data. The majority of participants worked in administrative roles, with only two of the 20 recruited having direct clothing industry experience. All were between $18-45$ years old and self-selecting as a UK size 10, 12 or 14. One participant self-identified as a size 14, eight as size 12 and eleven as 10 . It was not possible to ascertain why less women who were a size 14 volunteered for this study but speculatively it is possible that women who are smaller are more comfortable about talking about their bodies The limitation on size was implemented because dresses were purchased specifically for this study. Restricting the size range of the participants meant that a greater variety of 
dresses could be purchased with the limited funding that was available. Each participant was given a separate timeslot. Dress availability was a factor that required careful management in order to ensure there was one of an appropriate size available for everyone who participated. Participants were sent details explaining research procedures in advance and consent forms were completed before data collection. Women agreed for quotes to be used anonymously in reports.

\section{Retailer and garment selection}

Four retailers (H\&M; M\&S; Newlook; Topshop) were selected from a larger sample who matched the criteria of: providing dresses in sizes 10-14; having a national UK presence; providing primary sizing data online and having retail outlets marketing to consumers between $18-45$. Dresses were chosen because they have a fit relationship with the primary (bust) and secondary (waist and hip) dimensions used to designate clothing size to the customer (BSI 2002). A total of 24 dresses were purchased (Table 1) from the retailers where they had available stock in $10-14$. The dresses were selected in order to provide a wide selection of styles in order to replicate what would typically be available to them during a shopping visit to one of the selected retailers. Where possible, each style of dress was purchased in only one colour in order to differentiate between the influence of garment characteristics (style and colour) during the selection process. All the dresses were made from woven non-stretch fabric except one which was slightly stretchy due to its 3\% elastane fibre content. During the research garments were coded (Table 1) using either the codes on the swing ticket or a short abbreviated code to make managing data easier.

Insert Table 1 here,

\section{Coding of the participants to preserve anonymity}

Each participant was provided with a unique code, these codes were then converted to alphabetic letters and full names beginning with that letter for qualitative results relating to wearer perceptions. This coding retained the anonymity of the participants. 


\section{Qualitative data collection}

The initial stage was for each participant to select a dress from the seven different styles provided. They could try as many of the dresses on as they liked before they made their final decision. This stage was set up to mimic the decision-making processes that take place when a garment is purchased within a store. The selection stage was broken down in to two separate processes:

- assessment and selection from the rail when the garment was still on the hanger

- assessment of the dress on the body and the subsequent selection or rejection.

Women were provided with a private cubicle with a mirror. Once they had the dresses on they were joined by one of the researchers who audio recorded their observations as they tried the dresses on. A further short interview probed into their body image perceptions related to their selected garment. All the data were transcribed.

\section{Analysis of the results}

Although the aim of the larger interdisciplinary study was to investigate women's experiences of dress fit and body image, it became clear during the analysis that one particular dress was constantly rejected. This rejection was of particular concern for the apparel experts, both of whom have research interests in sizing and garment fit. Therefore a focused analysis was conducted to identify why the dress was rejected by so many. Keyword searches were initially used on the transcripts of the participants' observations made during the dress selection and fit trials in order to identify why the dress was rejected. To establish whether this rejection was related purely to fit problems or whether other factors influenced the rejection the data was coded to identify categories. Categories were then combined and relationships between the categories were explored.

\section{Findings}

\section{Rejection of the pink dress}

Twenty participants took part in the study. During stage one of the assessment, the pink dress was selected at least as many times as the other dresses. In fact exactly half of the participants (10) chose to try it on. Out of those who did not select it to try, eight did not mention why and two participants rejected the dress because of colour 
preference. Only one other dress was selected by more participants (11 times) and the dress selected the least number of times was tried on by four participants. All the other dress styles were tried on by either eight or nine participants. It was during stage two of the selection process, when the participants were assessing the garment on the body that the problems with the pink dress began to emerge. The most predominant theme was that of poor fit which caused or contributed to the rejection of the dress by all ten participants who tried the dress on. Colour preference also featured as an influential factor causing rejection. Themes and relationships between themes are illustrated in Figure 1.

Insert FIGURE 1 here:

\section{Fit rejection: Too tight: hips, thighs and buttocks}

The most common complaint from those who tried the pink dress was that it was too tight around the hips, buttocks and thighs. Eight out of the ten participants who tried the dress on experienced this fit problem. One participant complained about the dress being so tight across the hips, she couldn't get it on.

THERESA: I couldn't get it over my hips, I had to take it off again.

However even the next size up was considered to be too tight.

THERESA: This one goes on but I still had to pull it over my hips.

\section{Size code smaller than expected}

Seven participants found that the initial dress they tried was generally too small. Two could not even get the dress on. Only one of them went on to try the larger size, which was still too tight. Five participants were clearly perturbed when they found that the size that they initially selected was too small. Comments were indicative that slimness was perceived to be desirable and consequently misleading size coding contributed to making the women feel larger and less attractive.

ISABELLE: It's even tighter than the other one... it's not doing anything for my self esteem. 
PETRA: It's too small around my hips and bum ...[it makes me feel] ...not very attractive...yeh it makes me feel bigger

Some participants reacted indignantly at the idea that they had to try a larger size than normal.

QUEENIE: I've never been a size 14.

LISA: If this is a 10 , then it should be a breeze to put on.

\section{Too revealing: fit, style and fabric}

Seven of the participants complained that the dress was too revealing. Two of these comments related to the fact that it was too tight over the hip region.

ANNA: It's quite tight on my bum...Yeah, I don't want my ass on show.

Two participants were conscious that the fabric revealed their underwear and "lumps and bumps", whilst others were uncomfortable that the styling or cut of the dress revealed specific regions of their bodies that they preferred to conceal including: knees, cleavage and arms.

ANNA: I can just imagine giving everyone a good eyeful...from bending over. I get told off by my Mum and Dad."

\section{Shapeless: too loose on waist}

Many of the participants who said the dress was too tight on the hips also complained that the dress was too loose around the waist. This 'shapeless style' was considered to be unflattering. One participant realised that the dress was designed to be unfitted at the waist but it was not a style that she was usually attracted to.

OLIVIA: I usually go for a dress that has more of a waist but I suppose that's missing the point.

It was the combination of tight hips and loose waist that caused the most concern. 
ANNA: Gosh it's dead baggy round here [the waist]... Oh my god!

Do you remember I said about those ones that cling to your bum?

There it is, it's quite tight on my bum.“

\section{Shape: looser on the top}

The second issue relating to shape was that it tended to be looser around the top (bust, armholes, shoulder) than it was on the hips. A number of participants who complained about tightness around the hips were satisfied with the fit around the bust. More extreme examples of this problem also occurred with the dress being too tight on the hips and too loose on the top.

\section{Rejection: Colour}

In comparison to fit the influence of colour was minor. It caused 2 participants to reject the dress before trying it on and one participant was swayed by colour in her decision-making. The participants' comments indicate that colour preference in clothing is closely related to the enhancement of personal attraction. Participants had clear opinions about which colours suited them or enhanced attraction and which were perceived to deter it.

LISA: I tend to stay away from pinks and reds because they make me look pale.

One other colour subtheme emerged and that was the notion of seasonal colours. One participant was deterred from taking the dress because the colour was one she associated with summer, thus limiting its wearable lifespan.

THERESA: It's more of a summery dress, so if it was a dark dress, more of a wintry colour, I think I could wear it with black or dark brown tights and boots. 


\section{Discussion}

\section{The importance of fit}

The analysis highlights some important issues relating to fit. Firstly, although none of the women selected the pink dress to keep, half of them selected it to try on. This is worth noting because it identifies the difference between how women assess clothing on and off their bodies. The study demonstrates that it is only once a garment is on the body that the decision about purchase is made. This concurs with Eckman et al. (1990) who found that women initially selected dresses using a different set of criteria to the criteria used in the changing room. In the context of online retailing, these findings highlight the difficulty of meaningful consumer assessment of a garment before purchase. It helps to explain why the percentage of women returning clothing is reported to be as high as $54 \%$ (Mintel 2015). In a similar way to catalogue purchase, online retailing forces the secondary and crucial assessment of a garment on the body to be conducted at home, only after the purchase has taken place.

The findings of this study not only demonstrate how important it is for women to assess a garment on the body prior to purchase but it also reveals that women have a clear idea of what they expect from a garment in terms of fit. This concurs with previous studies (Shim and Bickle 1993; De Klerk and Tselepis 2007; Apeagyei 2008; Grogan et al. 2013) and indeed familiar themes emerged from the analysis: the preference for flattering garment shapes, specifically those that enhanced the waist and emphasised or created an hourglass body shape. The rejection of anything that was too tight, too revealing and therefore inappropriate and a preference for a proportionally balanced body shape.

The findings also add evidence to support the claim that the use of fit models in industry is outmoded and inappropriate and the cause of fit problems for anyone who does not conform to the body shape of the model (Ashdown and O'Connell 2006; Bye et al., 2008; Brownbridge 2012). Shim and Bickle (1993) who conducted a much larger qualitative study identified length of trousers, skirts and dresses as being the primary cause of fit dissatisfaction. The results from this study focus more on girth measurements. The rejected dress did not conform to any of the participants' body shapes. This nonconformity was however consistent in that it was too tight on all the participants' hips and either too loose or fitted across their bust. Speculatively, this dress was developed for a fit model with a very different body shape to that of the 
participants in this study. This observation may appear to be contradicted by the acceptance of the second dress from the same retailer (H\&M) by three of the participants. Both dresses were pink, would presumably conform to the same size specification and potentially be fitted on the same fit model. The rejected dress however was a shift shape, styled to skim over the hips and made from a non-stretch woven fabric. The accepted dress was a button through shirt dress that flared slightly from the hips and was made from a stretch cotton sateen. This comparison indicates that good fit is more crucial for some garment styles than others. In this case the shirt dress was still tight across the participants hips but the inclusion of elastane in the fabric and the flared skirt prevented the participants rejecting the dress.

Finally the size coding on the pink dress was also problematic. When the participants tried the dress on and it was tighter than they expected, their responses indicated that they were frustrated by what they considered to be misleading information. There was also evidence to support the theory that women identify with their clothes' size (Grogan 2016) and when this link is disrupted and the familiar size is replaced by a larger size it causes discomfort and body dissatisfaction. The frustration of being misinformed and the feelings of discomfort both contributed to the dress being rejected. Size coding is a complex issue and this finding indicates that garments that have been coded smaller than the prospective purchaser expects are more likely to be rejected. It is well documented that many retailers avoid this pitfall by implementing vanity sizing, in order to flatter women into purchasing (Treleavan 2006). Paradoxically, although vanity sizing may please women and influence them to purchase, it also increases sizing inconsistency amongst retailers, which increases frustration for consumers, prevents purchase and increases the risk of returns (Labat, 2007; Kennedy, 2008). Findings from this study show that women can feel disappointed and deflated when they find that the size number on the label of the garment they are trying does not match the size they identify with. These sizing numbers can actually have a very tenuous relationship to how a garment fits and negative feelings invoked by the number on the label appears to contribute to the rejection of the garment. This finding supports Kinley (2003) who suggested that retailers de-emphasise the number on the size label in order to focus on achieving comfort through appropriate fit. 


\section{Poor fit and its contribution to textiles waste}

This small-scale study provides insight into how sizing, a very specific area of clothing practice can contribute to waste and pollution. As the debate around the fashion industry's contribution to non-sustainability matures (Cataldi et al., 2013; Fletcher 2014; Binotta and Payne 2017), it is important that specific problems that contribute to poor practice and result in waste are identified. Only then can real initiatives for improvements be implemented. This is already starting to happen as individual experts from particular fields of research start to acknowledge the environmental impacts caused by established methods of practice. Cassidy, (2013) for instance suggests that current methods of colour forecasting should be amended in order to consider customer preference and therefore limit levels of unsold stock due to the use of colour that does not appeal.

Even when sustainable manufacturing practice is used, the application of flawed sizing practice, resulting in garments that do not fit compromises sustainability. Evidence from this study suggests that garments are currently being produced that do not fit a large proportion of the population. There is clearly a need for a different, more considered and accurate approach.

\section{Speculative practice leading to waste}

The fashion supply chain currently works on a system where the provider (retailer) decides what to produce and the consumer selects from this predetermined offer. In order to develop fashion goods, a complex number of processes must take place, all requiring skills, knowledge and the acquisition of appropriate data. Sizing is just one of these processes. This system is not fail-safe and consequently every time a batch of garments is produced, the retailer is taking a risk on whether the batch will sell through. The demand for ever increasing efficiencies creates a situation where personnel are expected to work shifts of 12-15 hours (Grose, 2013) and therefore decisions are often made under extreme pressure. In addition to this highly pressurised environment, problematic and underdeveloped systems such as those used to size mass-produced (Aldrich 2007; Ashdown 2014) clothing add to the risk that a product line will not sell. 


\section{Conclusions}

This small-scale study set out to understand why women rejected one particular dress, as a way to investigate broader issues around clothing rejection and clothes waste. Poor fit of the target dress was the predominant theme in interviews with women who rejected the dress, and women were frustrated at inaccurate sizing information. Lack of fit linked with body dissatisfaction as a result of the dress being tighter than expected. Consumers need to be able to read some kind of coding system in order to identify their size, however it is clear that the current sizing chaos is no nearer being solved despite many attempts to do so. This study demonstrates how current systems of numerical size coding can contribute to a the rejection of garments. Further research to develop and evaluate less emotive and more informed systems of coding are necessary. In addition, manufacturers appear to be unable or unwilling to sacrifice the perceived need to minimise the amount of sizes produced in order to facilitate systems that cater for greater size diversity. Further qualitative research would help to gain insight into why it is so difficult to create change within the fashion industry. In addition to this, consumer research is needed on sizing communication and coding systems in order for any meaningful improvement to be made.

Poor clothes fit has important implications for creating clothes waste and this study demonstrates a link between poor sizing practice and textiles waste. Further research is needed in order to gain insight into the extent of this issue. Very little known about how retailers deal with this issue and it remains hidden. Research that tackles this problem and brings it into the public sphere is needed.

\section{References}

Aldrich, W. (2007) "History of Sizing Systems and Ready-to-wear Garments" in Ashdown, S. (Ed.), Sizing in Clothing Developing Effective Sizing Systems for Readyto-wear Clothing, Cambridge, Woodhead Publishing.

Ashdown, S. (1998) "An Investigation of the Structure of Sizing Systems. A Comparison of Three Dimensional Optimized Sizing Systems Generated from Anthropometrical Data with the ASTM Standard D5585-94", International Journal of Clothing Technology, Vol 10, No. 5, pp 324-341. 
Ashdown, S.P. and O'Connell, E.K. (2006) 'Comparison of Test Protocols for Judging the Fit of Mature Women's Apparel'. International Textile \& Apparel Association, Vol. 24, Issue 2, pp. 137-145.

Ashdown, S. (2014) "Creation of Ready Made Clothing: the development and future of sizing systems" in Faust, M. E. and Carrier S. (Ed.), Designing Apparel for Consumers, Woodhead Publishing

Apeagyei, P.R. (2008) "Significance of body image among UK female fashion consumers; The cult of size zero, the skinny trend". International Journal of Fashion Design Technology and Education, Vol. 1, Issue 1, pp. 3-11.

Beard N. D. (2008) "The Branding of Ethical Fashion and the Consumer: A Luxury or Mass-market Reality?", Fashion Theory Vol. 12 Issue 4, pp 447-467

Beazley, A. (1997) "Size and Fit: Formulation of Body Measurement Tables and Sizing Systems- Part 2", Journal of Fashion Marketing and Management, Vol 2, No 3, pp 260-284.

Binotta, C. and Payne A. (2017) "Fashion Practice in the Context of Waste" Fashion Practice, Vol. 9, Issue 1 pp 5-29

Bougourd, J. (2007) "Sizing Systems, Fit models and Target Markets" in Ashdown, S. (Ed.), Sizing in Clothing Developing Effective Sizing Systems for Ready-to-wear Clothing, Cambridge, Woodhead Publishing.

British Standard (2002) "Size Designation of Clothes - Primary and secondary Dimensions" BS EN 13402 BSI

Brownbridge, K, (2012) "The Development of a Conceptual Model for Anthropometric Practices and Applications Regarding Complete Garment Technology for the UK Women's Knitwear Industry" Thesis in partial fulfillment of a $\mathrm{PhD}$ Manchester Metropolitan University

Brownbridge, K. Gill, S and Sanderson, R. (2014) "Aspirational Bodies: fashioning new beauty ideals" Paper presented at Beauty 4, Interdisciplinary.net, Mansfield College, Oxford, UK, 20 September - 22 September

Bye, E., Labat, K., McKinney, E., and Kin, D.E. (2008) “Optimised pattern grading. International Journal of Clothing and Technology, Vol 20, No 2 pp79-92

Cassidy, T. (2013). "Sustainable Colour Forecasting" in Sustainability in Fashion and Textiles: Values, Design, Production and Consumption Gardetti, M., A. and Torres A. L. (Ed.), Greenleaf Publishing, Sheffield, UK. 
Cataldi, C. Dickenson, M. and Grover, C. (2013) "Slow Fashion: Tailoring a Strategic Approach for Sustainability" in Sustainability in Fashion and Textiles: Values, Design, Production and Consumption Gardetti, M., A. and Torres A. L. (Ed.), Greenleaf Publishing, Sheffield, UK.

Chen H. L. and Burns L. D. (2006) "Environmental Analysis of textiles Products", Clothing and Research textiles Journal, Vol 24, Issue 3, pp 268-361

de Klerk, H. M. and Tselepis, T. (2007) "The early- adolescent female clothing consumer: Expectations. Evaluation and satisfaction with fit as part of the appreciation of clothing quality"

Dwyer, J. (2010) “A Clothing Clearance Where More Than Just Prices Have Been Slashed" The New York Times Http://www.nytimes.com/2010/01/06/nyregion, accessed June 242015

Eckman, M., Damhorst M. L., and Kadolph S. J. (1990) "Toward a Model of the InStore Purchase Decision Process: Consumer Use of Criteria for Evaluating Women's Apparel Clothing and textiles Research journal, Vol 8, Issue 2, pp 13-22

Fletcher, K. (2010) "Slow Fashion: an invitation for system change" Fashion Practice Vol 2. Issue 2. pp 259-265

Fletcher, K. (2014) Sustainable Fashion and Textiles Routledge, London.

Fox, I. (2007) Size matters The guardian online accessed 15.08.2011.

Gill, S. (2009) "Determination of functional ease allowances using anthropometric measurement for application in pattern construction", Thesis in partial fulfillment of a $\mathrm{PhD}$ Manchester Metropolitan University

Gill, S. 2015. "A Review of Research and Innovation in Garment Sizing, Prototyping and Fitting." Textile Progress 47 (1). Taylor \& Francis: 1-85.

Gill S. and Brownbridge, K. (2015) The Truth of standard sizing, in The Body Beautiful? Identity, Fashion and the Contemporary Female Body, Interdisciplinary.net 01.11 .15

Goody, A. (2016) Womenswear - UK - May 2016, Mintel retrieved October 142016 http://www.academic.mintel.com

Gribbin, E. A. (2014) "Body Shape and its Influence on Apparel Size and Consumer Choices" in Faust, Marie Eve. and Carrier Serge. (Ed.), Designing Apparel for Consumers, Woodhead Publishing

Grogan, S. (2016) Understanding Body Image in Men, Women and Children (3 Ed.), Routledge, Tailor and Francis Group, London and New York. 
Grogan, S., Gill, S. Brownbridge, K. Kilgariff, S. and Whalley, A. (2013) "Dress Fit and Body Image: A Thematic Analysis of Women's Accounts During and After Trying Dresses On”, Body Image Vol 03, Issue 003, pp380-388

Grose, L. (2013) "Wisdom from the Fashion Trenches" in Sustainability in Fashion and Textiles: Values, Design, Production and Consumption Gardetti, M., A. and Torres A. L. (Ed.), Greenleaf Publishing, Sheffield, UK.

Jenkyn Jones, S. (2005) "Fashion Design". (2 ed.), Laurence King Puiblishing, London.

Joy A. Sherry, J. F., Venkatesh, A., Wang, J. and Chan, R. (2012) "Fast Fashion, Sustainability and the Ethical Appeal of Luxury Brands", Fashion Theory, Vol 16 Issue 3. pp 273-295

Kemsley, W. (1957) "Women's Measurement and Sizes: A Study Sponsored by the Joint Clothing Council Limited", Her Majesty's Stationary Office, London

Kennedy, K. (2009) "What Size am I? Decoding Women's Clothing Standards" Journal of Fashion Theory Vol 13, Issue 9, pp 511-530

Kim, H. and Damhorst M. L. (2010) "The Relationship of Body-Related SelfDiscrepancy to Body Dissatisfaction, Apparel Involvement, Concerns with Fit and Size of Garments and Purchase Intentions in Online Apparel Shopping" Clothing and Textiles Research Journal Vol 28 No 4. pp 239-254

King, K. M. (2014) "National Sizing Surveys: techniques, data analysis and apparel product development" in Faust, Marie Eve. and Carrier Serge. (Ed.), Designing Apparel for Consumers, Woodhead Publishing

Kinley, T. R. (2003) "Size Variation in Women's Pants" Clothing and Textiles Research Journal Vol 21, Issue 1 pp 19-31

Kunick, P. (1984) Modern Sizing and Pattern Making for Women's Men's and Children's Garments London: Philip Kunick.

LaBat, K.L. and DeLong, M.R., 1990. "Body cathexis and satisfaction with fit of apparel", Clothing and Textiles Research Journal, Vol 8 No 2, pp.43-48.

Lapolla, K. and Sanders, E. B. (2015) "Using Cocreation to Engage Everyday Creativity in Reusing and Repairing Apparel" Clothing and Textiles Research Journal Vol 33 No. 3, pp 183-198

Lee, Y. and Sontag, M. S. "An Assessment of the Proximity of Clothing to Self-Scale for Older Persons", International Journal of Consumer Studies, Vol 34, Issue 4, pp $443-448$ 
Lee, Y. J., Istook, C. Yun, J. N. and Sun, M. P. (2007) "Comparison of Body Shape between USA and Korean Women", International Journal of Clothing Science and Technology, Vol 19, No. 5, pp 374-391.

O'Brian, R. and Shelton, W. C. (1941) "Women's Measurements for Garment and Pattern Construction", United States Department of Agriculture.

Pisut G. and O'Connell, L. J. (2007) "Fit Preferences of Female Consumers in the USA. Journal of Fashion Marketing and Management, Vol 11 pp 366-376

Powell-Smith, A. (2012) What's your perfect fitting top skirt and dress on the highstreet? The Guardian online accessed 15.082016.

Ramamoorthy Kumar S., Persson, A., Skrifvars. M. (2014) "Reusing textile Waste as Reinforcements in Composites" Journal of Applied Polymer Science, Vol 131, No. 4 pp 60-87

Sanderson, R. and Gill, S. "Turning figure drawing on its head" Paper presented at The Power of Fashion, $16^{\text {th }}$ Annual IFFTI Conference, Bunka Gakuen, University.

Scaturro S. (2008), "Eco-tech Fashion: Rationalising Technology in Sustainable Fashion" Fashion Theory, Vol 12, Issue 4, pp 469-488

Schofield, N.A. and LaBat, K.L. (2005). "Exploring the Relationships of Grading, Sizing and Anthropometric Data", Clothing and Textiles Research Journal, Vol 23 No 1, pp.13-27.

Shim, S. and Bickle M. C. "Women 55 Years and Older as Catalog Shoppers: Satisfaction with Apparel Fit and Catalog Attributes" Clothing and Textiles Research Journal Vol 11 Issue 4, pp 53-64

Shabi, R. (2004) “One size fits all”, The guardian online accessed 15.08.2016.

Smithers, R. (2011) "So I'm an extra small? You could have fooled me" The Guardian online accessed 15.082016.

Street Porter, Janet. (2016) "No wonder women have body image problems when retailers like H\&M make them feel fat" The Independent online accessed 03.08.2016 Taylor, R. (2004) "XL: The shape of things to come" The Guardian on-line Accessed 15.02 .2016

Tamburrino, N. (1992a) “Apparel Sizing Issues, Part 1”. Bobbin, Vol. 33, pp. 44-46. Yu, W. (2004) "Human Anthropometrics and Sizing Systems" in Fan J., Yu, W. and Hunter, L. (Ed.), Clothing Apperance and Fit: Science and Technology Woodhead. Winks, J. (1997) Clothing Sizes International Standardisation, Manchester, The Textile Institute. 
Workman, J. E. (1991) "Body Measurement Specification for Fit Models as a Factor in Clothing Size Variation" Clothing and Textiles Research Journal, Issue 10, pp 1-13 Wren, P. and Gill, S. (2010) "Industry fit practices and the issues that impact on good garment fit" Paper presented $100^{\text {th }}$ Textile Institute World Conference, Vol 3 Conference Proceedings, Manchester, UK, NOV 02-04, 2010 


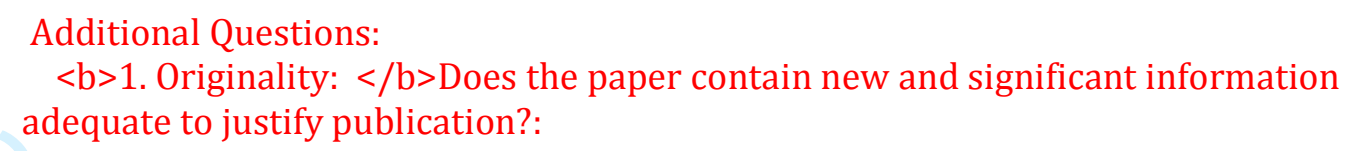

R1: It may not be as original as I was thinking, but it could, after modifications, be published.

Modifications in line with the reviewers comments have been included

$<b>2$. Relationship to Literature: $</ b>$ Does the paper demonstrate an adequate understanding of the relevant literature in the field and cite an appropriate range of literature sources? Is any significant work ignored?:

R1 - Interesting, besides 1941 and 1957 (two major documents) it covers paper and books from the last two decades. For whoever is familiar with the topic and for whoever is not, gets a good understating of the issue of sizing and fit.

$<\mathrm{b}>3$. Methodology: $</ \mathrm{b}>$ Is the paper's argument built on an appropriate base of theory, concepts or other ideas? Has the research or equivalent intellectual work on which the paper is based been well designed? Are the methods employed appropriate?:

\section{R1}

This part needs to be reveiw. The methodology seems to be all over the place. Besides, there is only 20 participants, which for me is ...

Context of the research approach needs to be more explicit.

- When, why recruiting this way.

- Why only 20 participants (lack of time? lack of budget?).

- Why recruiting women who considered themselves to be 10,12 or 14 ?

- Why was it more difficult to find women size 14 ?

- Why choosing one specific type of dress and not another?

- Why "of the same color when possible"?

- Criteria has to be the same if not, color may have an impact (as they mentioned).

These comments have been addressed p9\&10 (highlighted in red)

Methodology employed may be appropriate but many details needs to be mentioned and the whole section should be review.

\section{R2}

In Table 1, details of dresses, it would be very helpful to know what type of fabric the dresses were made from--knit, woven, stretch-woven? Fabric type can largely impact fit. This should be reported and discussed in the methods, results, and discussion. A short description of the fabric structure has been added (P10). The authors agree that fabric is an important factor in relation to fit, however this article focuses on the results from one dress and its rejection. This article does not attempt to do a thorough comparison between the participants responses to all the dresses. A further article addressing this is planned. 
$<\mathrm{b}>4$. Results: $</$ b $>$ Are results presented clearly and analysed appropriately? Do the conclusions adequately tie together the other elements of the paper?:

Results validate the literature. Although, again the section needs to be review. It has to be more detailed, more structured, and factual.

- Results also provides names of 7 of the 20 participants. Names should not be mentioned. It should be participant \#1, participant \#2, etc. Besides, Response - the coding system is explained on page 9 under coding of participants to preserve anonymity - (now highlighted in red).

- I would have liked to know the measurements of the 20 participants, the measurements of the garments, even maybe a photo of the dresses. It is not possible to include photographs of the dresses because the dresses were taken by the participants.

- As mentioned before, since dresses were not all of the same colors, it had an impact on why the dresses were rejected, which as I mentioned cause a bias to this study.

The study acknowledges that colour was an influential factor. It draws attention to the fact that two participants rejected the dress before trying it on because of the colour and then identifies two more instances when the colour of the dress influenced its rejection - P11 (highlighted in red)

- In the Discussion, 8.1 third paragraph, a point is made that the rejected dress must have been developed on a fit model that was not the same as the participants. However, there was another dress by the same manufacturer (H\&M) that was NOT rejected. So, it seems that this point cannot be valid. Consider whether it was the style, or the fabric causing the poor fit.

A paragraph has been added to explain this discrepancy. P15 (highlighted in red)

- Also, the dress measurements should be compared to the size chart measurements given by the company. Further analysis is needed into the reasons why this dress was rejected.

The authors agree that this is important however although this data was collected, the authors are currently working on a methodology that enables a valid comparison between body measurement, garment measurement and size chart measurement. This will be submitted as a separate article.

Furthermore, there are many missing citations. I can tell the author(s) are referencing back to studies mentioned in the literature review. These should be cited when they are mentioned again in the discussion--every time!

References have been added throughout the discussion (highlighted in red)

$<b>5$. Implications for research, practice and/or society: $</ b>$ Does the paper identify clearly any implications for research, practice and/or society? Does the paper bridge the gap between theory and practice? How can the research be used in practice (economic and commercial impact), in teaching, to influence public policy, in research (contributing to the body of knowledge)? What is the impact upon society (influencing 
public attitudes, affecting quality of life)? Are these implications consistent with the findings and conclusions of the paper?:

R1

Although I personally found the paper (as a whole) a bit weak, it identifies an implication for research, practice and/or society that is usually not being mentioned when sizing it discussed: "Contribution to textiles waste".

Indeed, it was mentioned many times in previous papers that the actual sizing system may cause frustration for women; may be confusing for manufacturers; may cause many returns, etc. but to my knowledge, publications do not discuss this important issue.

This being said, it should discuss the importance of providing better - more detailed information on the size label.

The authors agree that there is a real need for improved information on the size label and have added passages that draw attention to this issue in the discussion p16 and conclusions $\mathrm{p} 18$.

$\mathrm{R} 2$

- This section needs improvement. The authors should really consider and respond to all of the above questions.

- Additionally, I was quite surprised that there is no discussion of future research questions implied by these findings, as it seems that there would be several.

Some recommendations for future research have been added to the conclusions p18.

- Section 9 is only a summary of the findings. It gives only one vague conclusion. (e.g. what is meant by "improved" sizing system?) If the other suggested changes are made in terms of additional literature, discussion, and more in-depth analysis, I think you could come up with some more meaningful conclusions from this research.

The conclusions have been updated p18.

$<b>6$. Quality of Communication: $</ b>$ Does the paper clearly express its case, measured against the technical language of the fields and the expected knowledge of the journal's readership? Has attention been paid to the clarity of expression and readability, such as sentence structure, jargon use, acronyms, etc.:

R1

The whole paper needs to be review. So many misspelling, syntax errors, throughout the whole paper.

- For every reference there is at least 1 error, many times 3 and sometimes 5 in only one.

- Besides, references needs to be in alphabetic order. Ex. Ashdown, Aldrich then back to Ashdown. 
Corrections have been done and spell and grammar checks conducted.

\section{Additional Questions:}

$<b>1$. Originality: $</ b>$ Does the paper contain new and significant information adequate to justify publication?:

R2 - Yes. This paper does contain new and significant information adequate to justify publication.

- However, authors need to explain what their studies contribute, confirms, brings different information to light in comparison to Eckman, M., Damhorst, M. L., \& Kadolph, S. J. (1990). Toward a model of the in-store purchase decision process: Consumer use of criteria for evaluating women's apparel. Clothing and Textiles Research Journal, 8(2), 13-22. I don't think it is right to say that this study is the first to look at women's fitting room experiences.

Added to the literature review (p8 highlighted in red) and referred to in the discussion p15 (highlighted in red)

- Also, there is some talk in this paper of online shopping forcing these decisions to be made in-home. However, this is not a new phenomenon--it happened with catalog shopping. e.g. Shim, S., \& Bickle, M. C. (1993). Women 55 years and older as catalog shoppers: Satisfaction with apparel fit and catalog attributes. Clothing and Textiles Research Journal, 11(4), 53-64. How does the experience of shoppers evaluating apparel fit back then, relate to shoppers today?

Added to the literature review P7\&8 and discussion p15

$<\mathrm{b}>2$. Relationship to Literature: $</ \mathrm{b}>$ Does the paper demonstrate an adequate understanding of the relevant literature in the field and cite an appropriate range of literature sources? Is any significant work ignored?:

R2

- on Pg. 6 about line 10, It is indicated that "recently" this has led to a focus on slim female bodies. I do not think that this is a recent phenomenon. Do you have literature to support this point? If not, perhaps delete "recently".

This point is acknowledged by the authors who agree that this is a long standing issue and not a recent one. The word has been deleted (highlighted in red)

- Section 3 addresses sizing inconsistencies; however, it is not clear what is meant in terms of inconsistencies. There should be some discussion of how garment measurements are arrived at. It is the basic block which relates (more or less) to the body measurements, modified to create the current fashion style. Thus, there is body measurement, plus wearing ease, plus (or minus) style ease of the fashion. Relate all of these factors back to sizing inconsistency. Yes, this heading was not clear and has been changed and a couple of introductory sentences added (highlighted in red). The focus of this section was an overview of poor sizing provision across a broad market, rather than a detailed review of how garment measurements are arrived at on an individual level.

- When talking about the issue of inconsistency in size coding, you may also wish to address the Kinley, T. R. (2003). Size variation in women's pants. Clothing and Textiles Research Journal, 21(1), 19-31 research. 
This has been added p6 (highlighted in red) and in the discussion p16

- On page 5, about line 40 , there seems to be an unnecessary "s" at the end of the word female.

Amended (highlighted in red)

- In section 5, there is a significant amount of space discussing textile was that is NOT caused by fit problems. I'm not sure all of this is necessary.

The authors acknowledge that some of this section may not be directly related to fit but it is included because it adds context to the issue of textiles waste. I.e. because both textiles production and textiles waste in landfill can be so damaging to the environment the production of faulty garments through application of ill-conceived sizing systems is something that should be urgently addressed.

- You may also wish to include Bye's research on grading practices--which speaks to why it is such a bad idea to have a single size fit model for an entire size range. Bye, E., LaBat, K., McKinney, E., \& Kim, D. E. (2008). Optimized pattern grading. International Journal of Clothing Science and Technology, 20(2), 79-92.

A paragraph has been added P4 (highlighted in red)

R2

- The quality of the communication is very good, overall.

- As noted above, there are some definite opportunities for additional work/improvements. Overall, though, the present text is very well organized and well written. 